\title{
Burden and spectrum of bacterial infections among sickle cell disease children living in Cameroon
}

\author{
Anastasie Nicole Alima Yanda', Jobert Richie N. Nansseu ${ }^{1,2^{*}}$, Hubert Désiré Mbassi Awa ${ }^{1,2}$, Sandra A. Tatah ${ }^{1,2}$,
} Judith Seungue ${ }^{1}$, Charlotte Eposse ${ }^{3}$ and Paul Olivier N. Koki ${ }^{1,2}$

\begin{abstract}
Background: Although sickle cell disease (SCD) children are highly susceptible to bacterial infections (Bls), there is a dreadful lack of data related to the burden and spectrum of Bls in sub-Saharan Africa (SSA), the highest affected region with SCD. This study aimed to determine the burden and spectrum of Bls among SCD children hospitalized in a pediatric reference hospital in Cameroon, a SSA country.

Methods: We conducted a retrospective analysis of records of children hospitalized from November 2012 to August 2015 in the SCD unit of the Mother and Child Centre of the Chantal Biya Foundation, Cameroon. We enrolled all known SCD children aged 15 years or less, hospitalized for a suspicion of BI and who presented a positive culture of a body specimen.

Results: A total of 987 SCD children were hospitalized during the study period. Cultures were positive for 96 patients (9.7\%) among whom 60.4\% males. Ages ranged from 6 to 192 months with a median of 53 (Interquartile range (IQR) 21-101) months. For children no more covered by the Expanded Programme on Immunization, only 13 (18.8\%) had received the Pneumo $23^{\oplus}$ and Meningo A\& ${ }^{\oplus}$ antigens, and 12 (17.4\%), the Typhim vi ${ }^{\oplus}$ and the Haemophilus influenzae type $b$ antigens; 58 children (84.1\%) had received no vaccine. The specimen yielding positive cultures were: blood (70. $7 \%)$, urine (13.1\%), pus (9.1\%), synovial fluid (4.1\%), cerebrospinal fluid (2.0\%), and bone fragment (1.0\%). The different types of infection included: urinary tract infections (13.5\%), myositis (8.3\%), arthritis (6.3\%), osteomyelitis (4.2\%), and meningitis (2.1\%); the site of infection was unidentified in $65.6 \%$ of cases. The main bacteria included: Salmonella sp. (28.1\%), Staphylococcus sp. (18.8\%), Klebsiella pneumoniae (17.7\%), Escherichia coli (10.4\%), Enterobacter sp. (5.2\%), Acinetobacter sp. (4.2\%), Streptococcus sp. (4.2\%) and Serratia sp. (4.2\%).
\end{abstract}

Conclusion: This retrospective analysis revealed $9.7 \%$ cases of Bls, mainly caused by Salmonella sp. (28.1\%), Staphylococcus sp. (18.8\%), Klebsiella pneumoniae (17.7\%), and Escherichia coli (10.4\%).

Keywords: Sickle cell disease, Children, Bacterial infection, Cameroon

\section{Background}

Sickle Cell disease (SCD) also referred to as Sickle Cell Anemia, is the most widespread and severe monogenetic disorder in the world, specifically in Africa south of the Sahara where it constitutes a real public health issue with $1-4 \%$ of babies born affected [1-3]. In Cameroon,

\footnotetext{
* Correspondence: jobertrichie_nansseu@yahoo.fr

${ }^{1}$ Mother and Child Centre of the Chantal Biya Foundation, Yaoundé, Cameroon

${ }^{2}$ Faculty of Medicine and Biomedical Sciences, University of Yaoundé I, PO Box 1364, Yaoundé, Cameroon

Full list of author information is available at the end of the article
}

around $20 \%$ of the population carries the sickle cell trait [4], and the disease prevalence is estimated at $0.6 \%$ in the general population. It is estimated that almost 4000 babies will be born with a major sickle cell syndrome each year (unpublished data).

SCD is particularly disastrous, mainly due to its acute and chronic complications, including painful vasoocclusive events, cerebral vasculopathy, priapism, chronic kidney disease, acute chest syndrome, pulmonary hypertension and bacterial infections (BIs) among others [5-7]. Indeed, BIs are one of the prevailing complications of 
SCD and can occur either as an acute or a chronic condition. As such, they constitute a major cause of morbidity and mortality among SCD children and adults [8,9]. A 20-years prospective study showed for instance that BIs led to $20-50 \%$ of deaths among SCD patients [8]. The increased susceptibility of SCD patients to BIs is multifactorial, including: (i) a functional asplenia; (ii) a default in complement activation; (iii) micronutrient deficiencies; (iv) a genetic predisposition, and (v) mechanical risk factors [8].

The organisms most commonly isolated from children with SCD are: Streptococcus pneumoniae, non-typhi Salmonella sp., Haemophilus influenzae type b, Escherichia coli, Acinetobacter sp. and Klebsiella sp. [10, 11]. Evidence accumulated indicates a strong association between SCD and invasive bacterial disease among SCD Africans, especially greater for Streptococcus pneumoniae, nontyphi Salmonella $s p$. and Haemophilus influenzae type b $[11,12]$. Moreover, it has been claimed a predominance of invasive pneumococcal infections below the age of five, and salmonella infections above 5 years old $[13,14]$.

While sub-Saharan Africa (SSA) is the highest affected region with $\mathrm{SCD}$, there is a paradoxical dearth of data regarding the spectrum of BIs among SCD patients to guide the proper and efficient management of these threats across the region, especially in Cameroon, a SSA country. Willing to fill this critical gap, the present study was undertaken, the aim of which was to assess the burden and spectrum of BIs which have occurred among SCD children hospitalized in a pediatric reference hospital in Cameroon.

\section{Methods}

\section{Study design and setting}

We conducted a retrospective analysis of records of children hospitalized in the SCD unit of the Mother and Child Centre of the Chantal Biya Foundation from November 2012 to August 2015. This Centre, which has been well described elsewhere [7], is a pediatric reference hospital receiving patients coming from all over the country and the rest of the Central African subregion. Nearly 700 SCD patients are regularly followedup, with an average of 400 hospitalizations per year. The body specimens were analyzed at the Centre Pasteur of Cameroon. Located in Yaoundé and at a 2-min walking distance from the hospital, the Centre Pasteur of Cameroon is the laboratory of reference in the country; it uses international standard procedures and goes along a regular and rigorous internal and external control of quality.

\section{Study participants}

During the study period, we consecutively and exhaustively included all known SCD children aged 15 years or less, who have been hospitalized for a suspicion of BI and presented a positive result after culture of a body specimen (blood, urine, cerebrospinal fluid, bone fragment, synovial fluid or pus). Samples were collected in the unit and transported without delay to the Centre Pasteur of Cameroon where they were analyzed. Bacterial isolations were conducted using standard culture milieus such as Cystine Lactose Electrolyte Deficient, Chapman, Mac Conkey, chocolate (agar cooked/fresh blood), or polyvitex chocolate, depending on the type of specimen to be analyzed. Identification of the bacteria used different specific antibiotic galleries. Poly-microbial cultures were not considered in the present work, neither were contaminations (identified as positive cultures in patients with fever dropping without any antibiotherapy, or good remission with an antibiotherapy described, after the antibiogram, as resistant to the incriminated bacterium).

\section{Data collection}

We used a preconceived and standardized questionnaire for data abstraction. Data were collected on age, sex, vaccination status after the Expanded Programme on Immunization (EPI) (especially regarding Pneumo $23^{\circ}$, Meningo $\mathrm{A} \& \mathrm{C}^{\oplus}$, Haemophilus influenzae type $\mathrm{b}$ and Typhim $\mathrm{vi}^{\oplus}$ antigens), clinical signs and symptoms at presentation (fever, vaso-occlusive crises), site of infection and type of sampling performed, isolated bacterium, treatment and outcome in the course of hospitalization.

\section{Statistical methods}

Data were coded and entered using Microsoft Excel 2010, and analyzed with SPSS software version 20.0 (IBM SPSS Inc., Chicago, Illinois, USA). Results are presented as frequency (percentage) for qualitative variables, and median (interquartile range (IQR)) for quantitative ones. Comparison between qualitative variables used the Chi- 2 test, and results were considered statistically significant when $p<0.05$.

\section{Ethical statement}

Before commencing this study, authorizations were obtained from administrative authorities of the Mother and Child Centre, and an ethical clearance was granted by its Ethical Review Board. All the procedures used in the present study were in keeping with the current revision of the Helsinki Declaration. As the study was retrospective, patients' consents could not be obtained. However, the study was approved by the association of parents of SCD children of the Mother and Child Centre which includes the majority of parents of these diseased children formerly followed-up or hospitalized in the SCD unit. 


\section{Results}

On the whole, 987 children suffering from SCD were hospitalized during the study period; cultures were positive for 96 patients (9.7\%). Patients' ages ranged from 6 to 192 months, with a median of 53 (IQR 21-101) months. There were 58 males (60.4\%), hence a M/F sex ratio of $1.53 / 1$. Twenty seven children (28.1\%) were aged less than 24 months (Table 1). Among the 69 patients equal or above 24 months of age, only a few had received vaccine recalls after the EPI: 13 (18.8\%) for the Pneumo $23^{\circ}$ and Meningo $A \& C^{\circledast}$ antigens, and 12 (17.4\%) for the Typhim $\mathrm{vi}^{\oplus}$ and the Haemophilus influenzae type b antigens; 58

Table 1 Demographic characteristics, main symptoms and sites of infection

\begin{tabular}{|c|c|c|}
\hline Characteristic & Number & Percentage (\%) \\
\hline \multicolumn{3}{|l|}{ Age groups (years) } \\
\hline$<2$ & 27 & 28.1 \\
\hline$\geq 2$ & 69 & 71.9 \\
\hline \multicolumn{3}{|l|}{ Sex } \\
\hline Male & 58 & 60.4 \\
\hline Female & 38 & 39.6 \\
\hline \multicolumn{3}{|l|}{ Vaccination coverage } \\
\hline EPI (0 to 12 months) & 96 & 100.0 \\
\hline Overall coverage from 24 months $(N=69)$ & 11 & 15.9 \\
\hline Pneumo $23(N=69)$ & 13 & 18.8 \\
\hline Meningo $A \& C(N=69)$ & 13 & 18.8 \\
\hline Typhim vi $(N=69)$ & 12 & 17.4 \\
\hline Haemophilus influenzae type b $(N=69)$ & 12 & 17.4 \\
\hline Vaso-occlusive crises: yes/missing & $80 / 07$ & $83.3 / 7.3$ \\
\hline Fever: yes/missing & $90 / 00$ & $93.8 / 0.0$ \\
\hline \multicolumn{3}{|l|}{ Type of infection } \\
\hline Myositis & 08 & 8.3 \\
\hline Osteomyelitis & 04 & 4.2 \\
\hline Arthritis & 06 & 6.3 \\
\hline Urinary tract infection & 13 & 13.5 \\
\hline Meningitis & 02 & 2.1 \\
\hline Septicemia & 63 & 65.6 \\
\hline \multicolumn{3}{|l|}{ Body specimen cultured ${ }^{a}$} \\
\hline Blood & 66 & 68.8 \\
\hline Blood + synovial fluid & 01 & 1.0 \\
\hline Blood + bone fragment & 01 & 1.0 \\
\hline Blood + pus & 02 & 2.1 \\
\hline Pus & 07 & 7.3 \\
\hline Cerebrospinal fluid & 02 & 2.1 \\
\hline Urine & 13 & 13.6 \\
\hline Synovial fluid & 03 & 3.1 \\
\hline
\end{tabular}

EPI Expanded Programme on Immunization; ${ }^{2}$ Total: 99 specimen sampled for culture children $(84.1 \%)$ had received no vaccine (Table 1$)$. Fever was noticed among 90 patients (93.5\%), and vaso-occlusive crises were present among 80 children (83.3\%; Table 1).

The specimen yielding positive cultures were: blood (70.7\%), urine $(13.1 \%)$, pus $(9.1 \%)$, synovial fluid $(4.1 \%)$, cerebrospinal fluid (2.0\%), and bone fragment (1.0\%). The different types of infection were: urinary tract infections $(13.5 \%)$, myositis $(8.3 \%)$, arthritis $(6.3 \%)$, osteomyelitis $(4.2 \%)$, and meningitis $(2.1 \%)$. Besides, the site of infection was unidentified (bacterial septicemia) in 63 patients $(65.6 \%$; Table 1$)$. There was no difference between males and females $(p=0.779)$, and between the under-5 and $5+$ years old $(p=0.291)$ with regard to the type of infection.

Bacteria were Gram negative in 74 cases (77.1\%), with no difference between males and females $(p=0.396)$, and the under -5 and $5+$ years $(p=0.221)$. Table 2 is representative of the different bacteria recorded with regard to the type of infection presented. The main bacteria included: Salmonella sp. (28.1\%), Staphylococcus sp. (18.8\%), Klebsiella pneumoniae (17.7\%), Escherichia coli (10.4\%), Enterobacter sp. (5.2\%), Acinetobacter sp. (4.2\%), Streptococcus sp. (4.2\%), and Serratia sp. (4.2\%). The majority of cases of septicemias were caused by Staphylococcus sp. (24.6\%), Salmonella sp. (24.6\%) and Klebsiella pneumoniae (16.9\%). Escherichia coli was responsible for the majority of cases of urinary tract infections (53.8\%) and Salmonella sp., for all cases of myositis, The two cases of meningitis were caused by Streptococcus pneumoniae (Table 2). Moreover, five patients presented an infectious recurrence; the most common bacterium in cause was Staphylococcus sp., and the site of infection was not identified in the majority of cases (Table 3).

Noteworthy, the antibiotherapy, which was started after the sampling had been done and before waiting for bacteriological results, comprised: as first line ceftriaxone and gentamycin, and as second line ofloxacin/ciprofloxacin and amikacin (or licomycin, depending on the results of the antibiogram as soon as available). The outcome was favorable for 82 patients (85.4\%), but worse for the other ones among whom 4 patients ending up with osteo-articular sequelae (4.2\%); 7 patients $(7.3 \%)$ were transferred to undergo surgery (for osteomyelitis or myositis), and 3 patients (3.1\%) died. Duration of hospitalization in the SCD unit varied between 1 and 21 days with a median of 9 (IQR 8-12) days.

\section{Discussion}

Bacterial infections (BIs) are a major cause of morbidity and mortality among SCD children and adults [8], but there remains a crucial dearth of data regarding its burden in SSA countries such as Cameroon. We aimed to assess the burden and spectrum of BIs in our context. Results from the present retrospective analysis showed a 
Table 2 Different germs recorded considering the type of infection

\begin{tabular}{|c|c|c|c|c|c|c|c|}
\hline \multirow[t]{2}{*}{ Germ } & \multicolumn{6}{|c|}{ Type of infection } & \multirow[t]{2}{*}{ Tota } \\
\hline & Myositis & Osteomyelitis & Arthritis & Urinary tract infection & Meningitis & Septicemia & \\
\hline Acinetobacter baumanii & & & & & & 3 & 03 \\
\hline Acinetobacter (others) & & & & & & 1 & 01 \\
\hline Alloiococcus otitidis & & & & & & 1 & 01 \\
\hline Citrobacter koserii & & & & & & 1 & 01 \\
\hline Corynebacterium sp. & & & & & & 1 & 01 \\
\hline Enterobacter aerogenes & & & & & & 1 & 01 \\
\hline Enterobacter cloacae & & & 1 & & & 3 & 04 \\
\hline Enterococcus sp & & & & & & 1 & 01 \\
\hline Escherichia coli & & & & 7 & & 3 & 10 \\
\hline Klebsiella pneumoniae & & & 2 & 4 & & 11 & 17 \\
\hline Proteus mirabilis & & & & 1 & & & 01 \\
\hline Proteus vulgaris & & & & & & 1 & 01 \\
\hline Pseudomonas fluorescens & & & & 1 & & & 01 \\
\hline Salmonella dublin & & 1 & & & & 1 & 02 \\
\hline Salmonella enterica serovar stanleyville & & & 1 & & & 1 & 02 \\
\hline Salmonella enteritidis & 2 & & & & & 3 & 05 \\
\hline Salmonella sp. (others) & 5 & 1 & 1 & & & 9 & 16 \\
\hline Salmonella typhi & 1 & & 1 & & & & 02 \\
\hline Serratia liquefaciens & & 1 & & & & & 01 \\
\hline Serratia marcescens & & & & & & 3 & 03 \\
\hline Staphylococcus aureus & & 1 & & & & 1 & 02 \\
\hline Staphylococcus epidermidis & & & & & & 4 & 04 \\
\hline Staphylococcus haemolyticus & & & & & & 4 & 04 \\
\hline Staphylococcus hominis & & & & & & 6 & 06 \\
\hline Staphylococcus sciuri & & & & & & 1 & 01 \\
\hline Staphylococcus (others) & & & & & & 1 & 01 \\
\hline Streptococcus pneumoniae & & & & & 2 & & 02 \\
\hline Streptococcus of group C & & & & & & 1 & 01 \\
\hline Streptococcus (others) & & & & & & 1 & 01 \\
\hline
\end{tabular}

9.7\% prevalence of BIs, comparable to the $6 \%$ obtained by Williams et al. [11]. On the contrary, our findings are lower that what were observed by Diop et al. [15] and Diakité et al. [16], respectively $50 \%$ and $40 \%$. This low prevalence $(9.7 \%)$ could be explained by the fact that due to lack of financial means, many patients' parents were incapable of doing all the required exams. We noticed for instance that only $46.2 \%$ of the bacteriological tests required were performed. Furthermore and in the large majority of cases, only one blood culture (instead of at least three per patient) was performed, lowering therefore our probability of catching up the bacterium.

Table 3 Cases of infectious recurrence

\begin{tabular}{|c|c|c|c|c|c|c|}
\hline \multirow[t]{2}{*}{ Patient } & \multicolumn{3}{|l|}{ First episode } & \multicolumn{3}{|c|}{ Second episode } \\
\hline & Age (months) & Germ & Type of infection & Age (months) & Germ & Type of infection \\
\hline 1 & 11 & Staphylococcus sciuri & Septicemia & 21 & Staphylococcus haemolyticus & Septicemia \\
\hline 2 & 52 & Salmonella sp & Septicemia & 75 & Staphylococcus hominis & Septicemia \\
\hline 3 & 123 & Staphylococcus sp & Septicemia & 133 & Enterobacter cloaccae & Septicemia \\
\hline 4 & 159 & Enterobacter cloaccae & Arthritis & 170 & Corynebacterium sp & Septicemia \\
\hline 5 & 17 & Escherichia coli & Urinary tract infection & 28 & Escherichia coli & Urinary tract infection \\
\hline
\end{tabular}


Another point to be raised is that in Cameroon, newborns are not systematically screened for SCD. In this study we considered only known SCD patients, which could have underestimated the real burden of BIs in this vulnerable population.

In Cameroon indeed, newborn hemoglobinopathy testing is neither available nor implemented universally compared to developed countries. Only parents of SCD children who are being followed in specialized centers will be educated and counselled on infection prophylaxis with oral penicillin (to be paid by the parent), and to bring their children to the hospital when the temperature rises. Since 2011, the Prevenar $13^{\circ}$ vaccine was introduced in the Cameroon Expanded Programme on Immunization, which is administered free of charge to all children at 6, 10 and 14 weeks of age. Additionally, a 23 -valent pneumococcal vaccine as well as some others (Typhim vi, Meningo A\&C) are proposed at 24 months to SCD children who are followed-up, but it is not given free of charge; hence only parents who can afford will vaccinate their kids.

This explains perhaps why we observed in this study, a low vaccination coverage after the EPI, around 15.9\%. Similarly, previous African reports have bolstered a low vaccination coverage after the EPI in the young pediatric population, around $6.2-32.5 \%$ in the Gabonese public sector with pneumococcal antigen coverage equaling $0.8 \%$, and around $10.8-13 \%$ in Cameroon $[17,18]$. It is worth mentioning that our SCD children's parents are always sensitized and educated on the importance of vaccinating their vulnerable kids and reminded in this regard, with regular campaigns being organized by the association of parents of SCD children. However, the costs of vaccines remain high for a large majority of parents, perhaps justifying the low coverages we have witnessed. Subsidization of vaccinations could thereby constitute a valuable solution to increase the vaccination coverage in this group of children. Nevertheless, studies willing to capture the factors explaining these low coverages are warranted.

Most of bacteria (71.4\%) were identified through blood culture, blood being easily accessible to be sampled. Besides, a great number of infections including localized ones, have a bacteremic phase during which the bacterium can be picked up through culture of blood $[15,16]$. The majority of bacteria identified (77.1\%) were Gram negative, concurring with Diop et al.'s findings [15]. By contrast, Williams et al. observed a higher proportion of Gram positive bacteria (41\%), Streptococcus pneumoniae especially [11]. Our observations could be the result of the introduction of the Prevenar $13^{\circ}$ antigen in the Cameroon EPI since 2011, the antibio-prophylaxis (with oral penicillin) on which almost all children followed in the SCD unit and aged 2 to 5-6 years are placed, and the practice of self-medication with abusive and inappropriate intake of antibiotics. This access to non-prescribed antibiotics may have biased the different specimen culture results we obtained in this setting. It is therefore understandable why only 2 cases of $S$. pneumoniae infections were recorded; these two children who presented meningitis had neither received the Prevenar $13^{\circ}$ nor the Pneumo $23^{\circ}$ antigens.

The bacterial ecology was dominated by Salmonella sp. (28.1\%), corroborating previous reports [13, 15, 16, 19]. This predominance is related to the digestive translocation of Salmonellas (ischemic embrittlement) favored by microvascular occlusions [8, 10, 15, 16]. Many infections were also caused by Klebsiella pneumoniae (17.7\%), not often found in these proportions according to previous reports $[11,15,16]$. K. pneumoniae was the second bacterium responsible for urinary tract infections $(30.8 \%)$, in line with results from Asinobi et al. (18.9\%) and Mava et al. (24.6\%) [12, 20]. Escherichia coli was responsible for $10.4 \%$ of infections, mainly urinary tract infections (53.8\%) still concurring with the literature [12, 13, 20].

Acinetobacter sp. was the fourth bacterium reported by Williams et al., found in $7 \%$ of cases [11], hence almost comparable to the $4.2 \%$ we have recorded. Staphylococcus $s p$. was responsible for $18.8 \%$ of BIs, corroborating previous studies [13, 19, 21, 22]. These bacteria were mainly represented by those known to be commensals, hence a possibility of contaminations. In fact, due to lack of finances to perform more explorations, it was difficult to differentiate between real infections caused by these bacteria (identified through only one bacteriological exploration) and a simple contamination of the sample cultured. However, the concerned patients presented an inflammatory syndrome and got better only after proper and adapted antibiotherapy, confirming thereby the initial suspicion. The absence of $H$. influenzae infections in the present report may be explained by the introduction (in 2008) of three doses of the Haemophilus influenzae type b antigen in the Cameroon EPI, notably at 6,10 and 14 weeks of age, and perhaps abusive use of antibiotics as self-medication.

We recorded 5 cases of infectious recurrence reflecting the high susceptibility of SCD patients to BIs, driven by a functional asplenia, a default in complement activation, micronutrient deficiencies, and mechanical and genetic factors [8]. Three patients died: one 2 years old boy who died at $24 \mathrm{~h}$ of hospitalization from meningitis caused by Streptococcus pneumoniae, and a 5 years old male child at $48 \mathrm{~h}$ from a severe sepsis caused by a nontyphi Salmonella sp. The third case was a female child of 7 years who was suffering from a severe sepsis with multifocal sites caused by a non-hospital acquired multiresistant Enterobacter cloacae; she was transferred to the 
emergency care unit where she died after 3 months of hospitalization.

Unfortunately, this study presents a number of flaws. First, the retrospective analysis of this work precluded us from obtaining all the information necessary, and having a control group to investigate some factors driving the occurrence of BIs in our milieu. Second, parents' financial constraints and lack of funding impeded the realization of more bacteriological explorations which could have permitted to depict and confirm more cases of $\mathrm{BI}$; for the same reasons, only one blood culture (instead of at least three per patient) was performed for most patients, hence diminishing considerably our probability of catching up the causal agent. Moreover, a free access to non-prescribed antibiotics in our context may have constituted a source of bias towards our results. Third, our analyses are based only on known SCD children, in a context where newborns are not systematically screened for SCD; this could have led to an underestimation of the real burden of BIs. Fourth, SCD children were recruited from only one hospital, perhaps hindering the generalization of results obtained. Nonetheless, the study was conducted in a reference hospital with patients coming from all over the country and the Central African sub-region. Besides, the study period of almost 3 years permitted to record a great number of cases.

\section{Conclusion}

This 3-years retrospective analysis permitted to record 96 cases $(9.7 \%)$ of bacterial infections among SCD children living in Cameroon. The bacterial ecology was mainly represented by Salmonella sp. (28.1\%), Staphylococcus sp. (18.8\%), Klebsiella pneumoniae (17.7\%), Escherichia coli (10.4\%), Enterobacter sp. (5.2\%), Streptococcus sp. (4.2\%), Acinetobacter sp. (4.2\%), and Serratia sp. (4.2\%). Substantial efforts to vaccinate SCD children after 12 months of age (when they leave the EPI) and increase the vaccination coverage in this group of vulnerable children could help to reduce the burden of BIs in SCD children. Patient's parents should be continuously sensitized and educated on the importance of vaccinating their kids, observe the penicillin antibio-prophylaxis and bring their kids to the hospital as soon as the temperature rises. Our clinicians must be adequately trained to manage these infections, bearing in mind that broad spectrum antibiotherapy should be started without waiting for bacteriological results. On the other hand, we believe it is high time our Governments think of subsidizing the management of SCD children for those parents who cannot pay. Cost-benefit studies are warranted in this regard.

\section{Abbreviations}

BI: Bacterial infection; EPI: Expanded Programme on Immunization; IQR: Interquartile range; SCD: Sickle cell disease; SSA: Sub-Saharan Africa

\section{Acknowledgements}

The authors are indebted to the association of parents of sickle cell disease children of the Mother and Child Centre of the Chantal Biya Foundation for their support, as well as the nursing staff of the sickle cell disease unit of the just-cited Centre.

\section{Funding}

This work has not benefited from any source of funding or sponsorship.

\section{Availability of data and materials}

Data supporting the conclusions of this article are included within the article. Raw data will be made available on request addressed to any of the co-authors.

\section{Authors' contributions}

ANYA and JRNN conceived and designed the study, collected and analyzed the data, and drafted the manuscript. HDMA, SAT, CE, JS, and POKN critically reviewed and revised the manuscript. All authors approved the final version of the manuscript.

\section{Competing interests}

The authors declare that they have no competing interests.

Consent for publication

Not applicable.

Ethics approval and consent to participate

An ethical clearance was granted by the Ethical Review Board of the Mother and Child Centre of the Chantal Biya Foundation, Cameroon. As the study was retrospective, patients' consent to participate was waived by this Ethical Review Board.

\section{Publisher's Note}

Springer Nature remains neutral with regard to jurisdictional claims in published maps and institutional affiliations.

\section{Author details}

${ }^{1}$ Mother and Child Centre of the Chantal Biya Foundation, Yaoundé, Cameroon. ${ }^{2}$ Faculty of Medicine and Biomedical Sciences, University of Yaoundé I, PO Box 1364, Yaoundé, Cameroon. ${ }^{3}$ Douala Laquintinie Hospital, Douala, Cameroon.

Received: 26 April 2016 Accepted: 8 March 2017

Published online: 15 March 2017

\section{References}

1. Rees DC, Williams TN, Gladwin MT. Sickle-cell disease. Lancet. 2010;376: 2018-31.

2. Weatherall D, Hofman K, Rodgers G, Ruffin J, Hrynkow S. A case for developing north-south partnerships for research in sickle cell disease. Blood. 2005;105:921-3.

3. Aliyu ZY, Gordeuk V, Sachdev V, Babadoko A, Mamman Al, Akpanpe P, Attah E, Suleiman Y, Aliyu N, Yusuf J, et al. Prevalence and risk factors for pulmonary artery systolic hypertension among sickle cell disease patients in Nigeria. Am J Hematol. 2008:83:485-90.

4. Ama V, Kengne AP, Nansseu NJR, Nouthe B, Sobngwi E. Would sickle cell trait influence the metabolic control in sub-Saharan individuals with type 2 diabetes? Diabet Med. 2012;29(9):e334-7.

5. Panepinto JA, O'Mahar KM, DeBaun MR, Loberiza FR, Scott JP. Health-related quality of life in children with sickle cell disease: child and parent perception. Br J Haematol. 2005;130(3):437-44.

6. Miller AC, Gladwin MT. Pulmonary complications of sickle cell disease. Am J Respir Crit Care Med. 2012;185(11):1154-65.

7. Nansseu JR, Alima Yanda AN, Chelo D, Tatah SA, Mbassi Awa HD, Seungue J, Koki PO. The acute chest syndrome in Cameroonian children living with sickle cell disease. BMC Pediatr. 2015:15:131.

8. Booth C, Inusa B, Obaro SK. Infection in sickle cell disease: a review. Int J Infect Dis. 2010;14(1):e2-e12.

9. Platt OS, Brambilla DJ, Rosse WF, Milner PF, Castro O, Steinberg MH, Klug PP Mortality in sickle cell disease. Life expectancy and risk factors for early death. N Engl J Med. 1994;330(23):1639-44. 
10. Ramakrishnan M, Moïsi JC, Klugman KP, Iglesias JM, Grant LR, Mpoudi-Etame M, Levine OS. Increased risk of invasive bacterial infections in African people with sickle-cell disease: a systematic review and meta-analysis. Lancet Infect Dis. 2010;10(5):329-37.

11. Williams TN, Uyoga S, Macharia A, Ndila C, McAuley CF, Opi DH, Mwarumba S, Makani J, Komba A, Ndiritu MN, et al. Bacteraemia in Kenyan children with sickle-cell anaemia: a retrospective cohort and case-control study. Lancet. 2009;374(9698):1364-70.

12. Mava Y, Ambe JP, Bello M, Watila I, Nottidge VA. Urinary tract infection in febrile children with sickle cell anaemia. West Afr J Med. 2011;30(4):268-72.

13. Burnett MW, Bass JW, Cook BA. Etiology of osteomyelitis complicating sickle cell disease. Pediatrics. 1998;101(2):296-7.

14. Zarkowsky HS, Gallagher D, Gill FM, Wang WC, Falletta JM, Lande WM, Levy PS, Verter Jl, Wethers D. Bacteremia in sickle hemoglobinopathies. J Pediatr. 1986;109(4):579-85.

15. Diop S, Koffi G, N'Dahtz E, Allangba O, Aka Adjo MA, Sanogo I, Sangaré A. Infection profile in sickle cell anemia. Bull Soc Pathol Exot. 1997;90(5):339-41. [Article in French]

16. Diakité AA, Balilé H, Konaté I, Traoré A, Traore NL, Dicko FT, Touré A, Diakité FL, Togo B, Sylla M, et al. Invasive bacterial infections occurring to sickle cell children in Bamako, Mali. REMIM. 2015; [Article in French]

17. Ategbo S, Ngoungou EB, Koko J, Vierin Y, Zang Ndong CE, Moussavou Mouyama A. Immunization coverage of children aged 0 to 5 years in Libreville (Gabon). Sante. 2010;20(4):215-9. [Article in French]

18. Vougmo Meguejio Njua C, Nguefack F, Chelo D, Tejiokem M, Kago I, Kobela M. Booster doses outside of the expanded program on immunization in two schools in basic education in Yaounde, Cameroon. Pan Afr Med J. 2011;10:20. [Article in French]

19. Makani J, Mgaya J, Balandya E, Msami K, Soka D, Cox SE, Komba AN, Rwezaula S, Meda E, Muturi D, et al. Bacteraemia in sickle cell anaemia is associated with low haemoglobin: a report of 890 admissions to a tertiary hospital in Tanzania. Br J Haematol. 2015; [Epub ahead of print]

20. Asinobi AO, Fatunde OJ, Brown BJ, Osinusi K, Fasina NA. Urinary tract infection in febrile children with sickle cell anaemia in Ibadan, Nigeria. Ann Trop Paediatr. 2003;23(2):129-34.

21. Epps Jr CH. Bryant Dr, Coles MJ, Castro O: Osteomyelitis in patients who have sickle-cell disease. Diagnosis and management. J Bone Joint Surg Am. 1991;73(9):1281-94.

22. Souna BS, Abarchi H, Karadji SA. Osteomyelitis in drepanocytosis: epidemiology, diagnosis and treatment. 66 cases, Niamey. Mali Med. 2006;21(4):21-5. [Article in French]

\section{Submit your next manuscript to BioMed Central and we will help you at every step:}

- We accept pre-submission inquiries

- Our selector tool helps you to find the most relevant journal

- We provide round the clock customer support

- Convenient online submission

- Thorough peer review

- Inclusion in PubMed and all major indexing services

- Maximum visibility for your research

Submit your manuscript at www.biomedcentral.com/submit 